\title{
Application of Automated Stereo Warehouse in Military Aircraft Material Management
}

\author{
Xiaoxiao Wang, Ye Zhang, and Jiagang Du* \\ Four station system of aviation materials, Air Force Logistics College, 85 Xijie street, Xuzhou, Jiangsu,
} China

Keywords: Automatization; Stereoscopic warehouse; Military aviation equipment; Application; Warehouse management

\begin{abstract}
Automated three-dimensional warehouse is of great significance in the management of military aviation materials. This paper expounds the shortcomings of the current military aviation materials automatic three-dimensional inventory in the warehouse construction, such as late start, inconsistent standards, imperfect matching performance, small scale, low efficiency and so on, and puts forward corresponding solutions to these problems.
\end{abstract}

\section{Introduction}

With the continuous development of China's aviation industry, more and more new aircraft and supporting spare parts are used, and higher requirements are put forward for aviation material management. Warehousing management, as an important part of aviation material management, affects the level of aviation material management. Traditional air material warehouse cannot meet the requirements of modern air material management in the aspects of system layout, storage capacity, operation equipment, operation efficiency, information system, rapid response and service capability. Automated three-dimensional warehouse is a new warehouse system which adapts to economic development and overcomes the above problems and rises in modern times.

\section{Concept and Composition of Automatic Stereoscopic Warehouse}

Automated three-dimensional warehouse is a new concept in logistics warehousing. The use of stereoscopic warehouse equipment can realize high-level rationalization of warehouse, automation of access, and simplification of operation. The schematic diagram of automated warehouse is shown in Figure 1. Automated stereoscopic warehouse is a form with high technical level at present. The main body of the automated warehouse is composed of shelves, roadway stacking cranes, workbenches in (out) warehouses, automatic transportation in (out) and operation control systems. The rack is a building or structure of steel structure or reinforced concrete structure. The rack is a space of standard size. The roadway stacking crane passes through the roadway between the racks to complete the work of stock and pick-up. Computer and bar code technology are used in management.

The automatic stereoscopic storage plane diagram is shown in Figure 2. Automated Stereo Warehouse (AS/RS) is composed of three-dimensional shelves, stackers in railways, pallet conveyors in and out of warehouses, bar code reading system for dimension detection, communication system, automatic control system, computer monitoring system, computer management system and other distribution cabinets, pallets, regulating platforms and steel knots such as wire and cable bridge. Complex automation system composed of auxiliary equipment such as construction platform. Using the first-class integrated logistics concept, advanced control, bus, communication and information technology, through the coordinated action of the above equipment for warehousing operations. High-speed operation, simplified operation, diversified product storage options, full and effective use of space, greatly shorten the time of goods in and out of storage, inventory maintenance, maintenance quickly and accurately. 


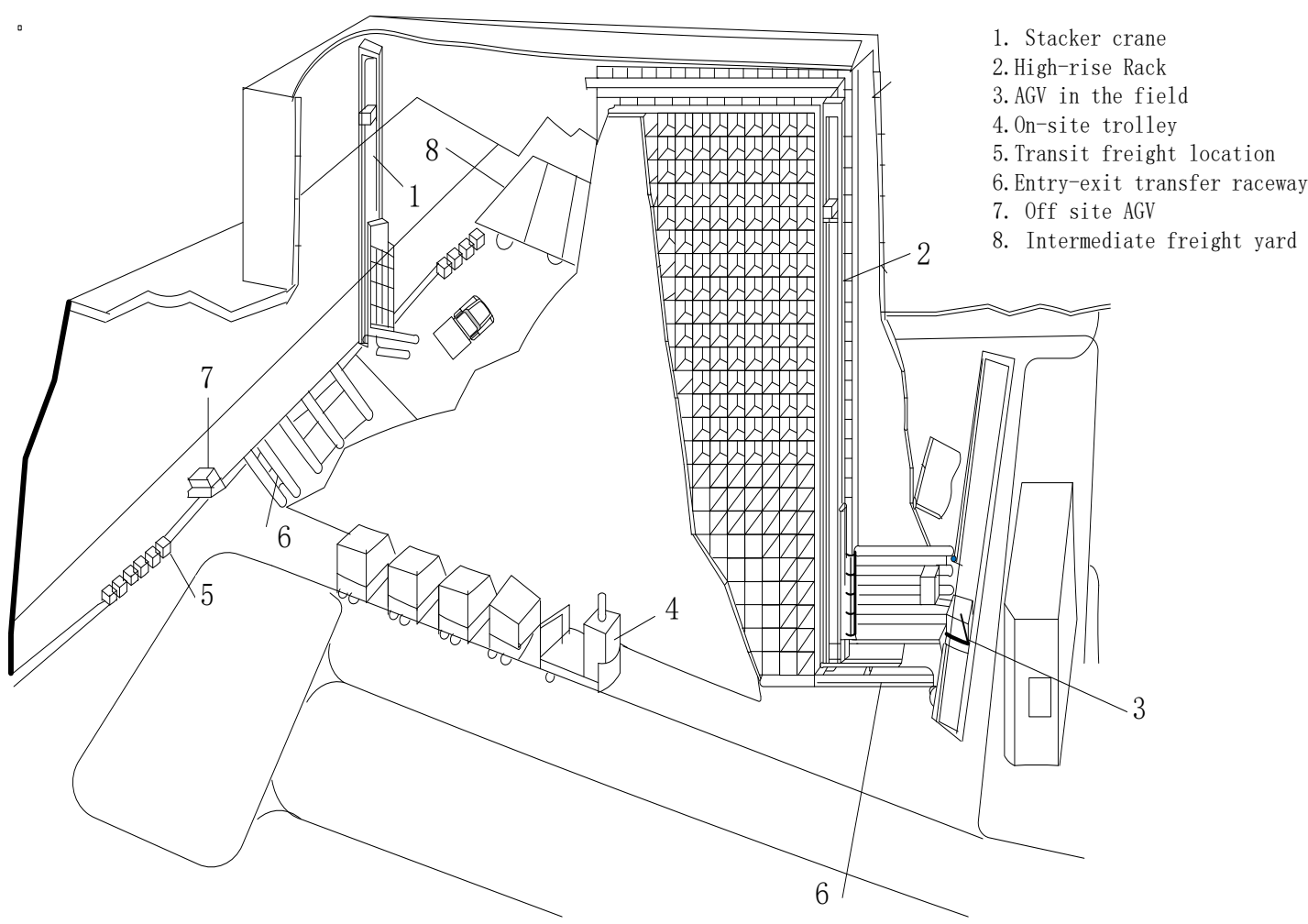

Figure 1 Schematic diagram of automated warehouse

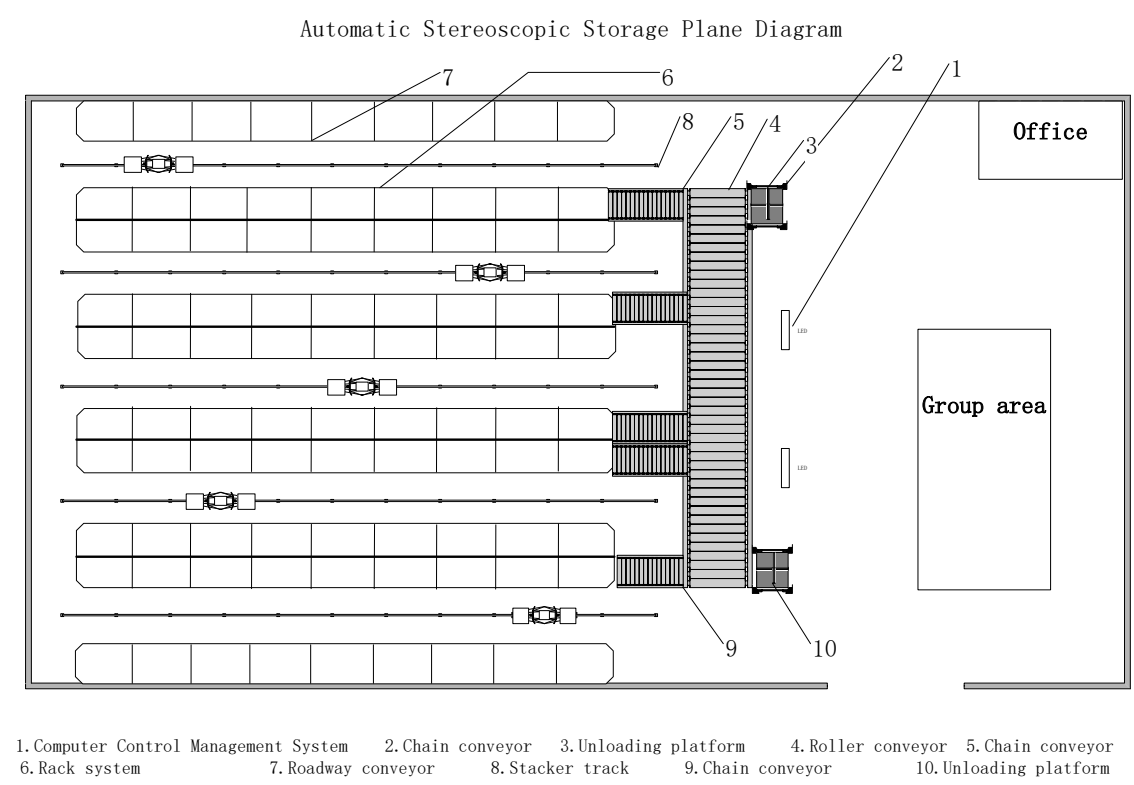

Figure 2 Automatic stereoscopic storage plane diagram

\section{Significance of the Construction of Military Aviation Material Automation Three-dimensional Storage}

The construction of military aviation material automation three-dimensional warehouse will play a certain role in warehouse management. First of all, the most important thing is to increase the storage capacity. Because the high-level shelves are used to store aviation materials in the automated warehouse, it can effectively reduce the area occupied by the warehouse, improve the utilization of space, and increase the storage capacity. Secondly, it improves the work efficiency. Automated three-dimensional warehouse uses use laneway stacker, transport or forklift truck for 
warehousing operations to achieve automatic access to aircraft materials, reduce the number of workers, reduce labor intensity, and improve operational efficiency. Thirdly, it improves the management level of aviation materials and promotes the modernization and management of aviation materials. Automated three-dimensional warehouse adopts computer management and control instead of traditional manual identification, search and statistics management mode, which reduces the error rate, improves the management level and guarantee ability of aviation materials, and realizes the computerization of management, automation of control and dynamic accounting management. Finally, it improves the storage environment of aviation materials and the working environment of personnel. The automatic three-dimensional warehouse uses use three-dimensional shelf storage. Aviation materials, avoiding the extrusion of aviation materials, the warehouse has good ventilation and ventilation effect, constant temperature and humidity, which greatly improves the storage and storage conditions of aviation materials and ensures the working environment of staff.

\section{Current Situation of the Construction of Automated Three-dimensional Storage of Military Aviation Materials in China}

(1) Warehouse construction started late. Due to the confidentiality requirements and the control of funds, the automatic three-dimensional warehouse is still in the stage of promotion in the warehouse construction of various units in China. The automated warehouse of military aviation materials was first put into use in the 1990s. However, due to its high investment cost, late maintenance investment and high demand for professional personnel, it has become the main obstacle to its promotion and application in military aviation materials management. At present, the warehouse of military aviation materials in our country is mainly ground warehouse, but with the continuous development of aviation industry, the types, quantities and types of military aviation materials are increasing. More and more, the traditional warehousing cannot meet the growing requirements of air material management, but due to the requirements of material types, security and other objective factors, not all units of air material management should use automated three-dimensional warehouse as the carrier for storage, therefore, our country's air material three-dimensional warehouse is still in the stage of promotion.

(2) The warehouse construction standards are not uniform and the management mechanism is not perfect. After long-term exploration, some military aviation materials production and use units have initially built automated three-dimensional warehouses. As far as its credit effect is concerned, there are some problems, such as inconsistent standards, imperfect management mechanism and so on. Automated stereoscopic warehouses of various units and departments are built on the basis of their own convenience and feasibility of use and management. The standard is not uniform and the degree of standardization is poor. In the process of construction, the functions and working principles of the built system are quite different due to the lack of strict implementation standards, which makes it difficult to realize interconnection and information sharing. In addition, the lack of standardized management system, regulations and standard use, maintenance and arbitrariness is very large, the intact rate of the system is reduced, and the operation cost is increased.

(3) The supporting performance needs to be improved. Automated storage/Retrieval system (AS/Rs) is also called automatic stereo library. The supporting support not only embodies in hardware, but also puts forward high requirements for software. At present, in the management of military aviation materials in our country. First, the information network is poor, and the automatic warehouse built by each unit is basically a closed and independent system, which is only operated by the internal personnel of the department, without considering the interconnection between the whole group company or the whole army's later visual system and logistics support system. Secondly, the ability of automatic identification is poor. At present, the application of bar code technology in military aviation materials management is still in its infancy, and the coding instructions of each unit are different. Therefore, in the process of procurement and management of aviation materials, almost all aircraft materials have no bar code identification, let alone other automatic identification equipment. Third, the system is not strong. It is difficult to optimize the 
built system because of the lack of advanced system simulation means and the lack of relevant experience accumulation, standardization and standardization of theoretical research [1].

(4) Small scale and scope, low efficiency. At present, through the observation of the three-dimensional warehouse of military aviation materials that has been built and put into use, it is found that: first, the number is small, mainly in the management of military aviation materials, the supporting manufacturers of military aviation materials are not built or used very much. Second, the scale is relatively small and the benefit is low. At present, the automatic three-dimensional warehouse of military aviation materials is limited to other professional aviation materials management, such as engine warehouse and ammunition warehouse has not yet been built. In addition, the current automated three-dimensional warehouse is limited to conventional roadway-type high-rise shelf warehouse, which has a large investment in equipment. Low storage density and high idle rate.

\section{Countermeasure to Strengthen the Construction of Aircraft Material Stereo Storage}

(1) Unified research according to demand. The design and completion of the automated warehouse should meet the actual needs of the task. Demand investigation and analysis is the premise and foundation of the design and construction of the automated warehouse, and is the key to the success of the construction. In the investigation and analysis, we should not only see the technical advantages and efficiency improvement brought about by the automated three-dimensional warehouse, but also see the cost increase in the process of operation and maintenance. We should proceed from the task requirements and the actual warehouse, and conduct a unified investigation and Research on the construction of the whole army and the whole group automated three-dimensional warehouse. Analysis, find out the needs, avoid building "Big Mac" projects that exceed the affordability and maintenance capacity, and cannot build "flower shelf" projects that look good and do not apply.

(2) Standard first and standard construction. The standardization of logistics information is the premise of realizing the interconnection and interoperability of logistics support system for military aviation materials. It includes standardization of aviation material coding, one-dimensional and two-dimensional barcode coding, and radio frequency identification tag coding. Standardization and standardization of interface of management information system etc. At present, the construction of military aeronautical material automation stereo warehouse in our country has entered a critical period of large-scale development. In order to avoid the disunity of standards, disunity of information system interface, interconnection, difficulty of information sharing and high maintenance cost in the construction of stereo warehouse, all units and departments should implement the disunity of standards. To solve these problems, we must strengthen standards and formulate industry norms and standards as soon as possible. At the same time, we should strengthen the implementation of existing standards and norms. For phase less. The relevant national standards or international standards may be consulted for the purpose of improving and unifying the various standards as soon as possible.

(3) Focus on the long-term and cultivate talents. Automated three-dimensional warehouse is a complex with high scientific and technological content. It requires high professional quality and inherent ability of personnel engaged in operation, management and maintenance. It is necessary to establish a set of perfect talent training mechanism and lay a solid foundation for talent team construction. From the past practice, depending on the technical force hired outside to achieve the maintenance and maintenance of automated three-dimensional storehouse, not only increases the financial burden, but also is not conducive to security and confidentiality work. In addition, because of the high failure rate and the untimely maintenance in the work, it not only affects the normal operation of daily work, but also fails to give full play to the advantages of automated three-dimensional library, which greatly weakens the comprehensive support efficiency of aviation materials [2].

(4) Keep abreast of the frontier and seek development. The establishment of automated warehouse depends on the development of logistics engineering, inventory strategy, military 
logistics supply chain, integrated computer aided design, radio frequency identification system policy and advanced theory and technology of planning and scheduling in the world. We should follow the trend of world development and follow the development of advanced technology of logistics support system in foreign military. Dynamic. Based on our own country and independent innovation, we should do a good job of technical reserve and basic research work in order to find the military aviation material automatic three-dimensional warehouse suitable for our national conditions [3].

\section{Conclusion}

The emergence and application of automated warehouse has improved the level of automation and informatization, and changed the traditional concept of warehouse management. With the continuous development of China's aviation industry, the automatic three-dimensional warehouse, a new storage form, will be widely promoted and applied in the management of military aviation materials.

\section{References}

[1] Wang Jianhong, Wang Meng, Xu Haitao. The construction of our army's automated warehouse exists Problems and Solutions. Military Logistics, 2012, (2): 24-25.

[2] Zhang Dengbin, Li Li, Yang Jiangen. Automated three-dimensional warehouse in military equipment Application of Material Management. Science and Technology Information, 2014, (5): 100.

[3] Wang Weiguo, Huang Weiping. Existing in the construction of our army's automated three-dimensional warehouse Problems and Countermeasures. Warehousing Management and Technology, 2007, (2): 26-27. 